\title{
The level of secretory leukocyte protease inhibitor is decreased in metastatic head and neck squamous cell carcinoma
}

\author{
CHRISTIAN CORDES $^{1 *}$, ROBERT HÄSLER $^{2 *}$, CHRISTIAN WERNER $^{1}$, \\ TIBOR GÖRÖGH ${ }^{1}$, CHRISTOPH RÖCKEN ${ }^{3}$, LENA HEBEBRAND ${ }^{1}$, W. MARTIN KAST ${ }^{4}$, \\ MARKUS HOFFMANN $^{1}$, STEFAN SCHREIBER ${ }^{2}$ and PETRA AMBROSCH ${ }^{1}$
}

\author{
${ }^{1}$ Department of Otorhinolaryngology, Head and Neck Surgery, Christian-Albrechts-University Kiel, Arnold-Heller- \\ Strasse 3, House 27, 24105 Kiel; ${ }^{2}$ Institute for Clinical Molecular Biology, Christian-Albrechts-University Kiel, \\ Michaelisstrasse 5; ${ }^{3}$ Institute of Pathology, Christian-Albrechts-University Kiel, Arnold-Heller-Strasse 3, House 14, \\ 24105 Kiel, Germany; ${ }^{4}$ Department of Molecular Microbiology and Immunology and Norris Comprehensive \\ Cancer Center, University of Southern California, 1450 Biggy Street, Los Angeles, CA 90033, USA
}

Received December 17, 2010; Accepted February 28, 2011

DOI: 10.3892/ijo.2011.1006

\begin{abstract}
Head and neck squamous cell carcinomas (HNSCC) represent the sixth largest group among all human malignancies. However, the exact molecular mechanisms inducing the genesis and the progression of metastasis in these tumors are poorly understood. The identification of molecular alterations involved in metastasis of HNSCC might influence the value of clinical diagnostics, impact therapy strategies and finally improve the prognosis of the patients. The purpose of this study was to identify clinically relevant alterations at the transcriptional and translational levels, when comparing metastatic $(\mathrm{N}+)$ and non-metastatic (N0) primary HNSCC. Three transcripts HERPUD1, SLPI and RAD51 were selected for further validation based on their association with carcinogenesis and metastasis. Quantitative real-time-PCR was performed to determine the mRNA expression levels. For subsequent confirmation of the results, immunohistochemistry was performed applying a monoclonal anti-SLPI antibody on 121 HNSCC tumor specimens ( $\mathrm{N} 0, \mathrm{n}=40 ; \mathrm{N}+, \mathrm{n}=81$ ). In metastatic primary cancer, SLPI mRNA showed 5.9-fold lower expression in comparison with non-metastatic primary cancer $(\mathrm{p}=0.0092)$. Immunohistochemical staining revealed a fold change of -1.79 between the $\mathrm{N}+$ and the $\mathrm{N} 0$ group $(\mathrm{p}=0.0002)$. The results presented here clearly indicate the repression of SLPI, measurable on both, mRNA and protein levels in metastatic primary
\end{abstract}

Correspondence to: Dr Christian Cordes, Department of Otorhinolaryngology, Head and Neck Surgery, Christian-Albrechts-University Kiel, Arnold-Heller-Strasse 3, Haus 27, 24105 Kiel, Germany

E-mail: ccordes@hno.uni-kiel.de

*Contributed equally

Key words: secretory leukocyte protease inhibitor, metastases, antileukoprotease, head and neck squamous cell carcinoma
HNSCC as compared to non-metastatic HNSCC. Therefore, it can be assumed that SLPI might have a substantial protective effect on the metastasis process of HNSCC.

\section{Introduction}

Head and neck malignancies account for approximately $6 \%$ of all malignancies, the majority of which resemble head and neck squamous cell carcinomas (HNSCC). The worldwide death incidence for head and neck cancer is estimated to be 350,000 per year (1). The molecular mechanisms of tumor initiation and progression including metastasis in HNSCC are poorly understood (2). However, gaining knowledge on the mechanisms influencing tumor progression constitutes the basis to develop innovative treatment strategies improving the patients' course of disease. As with other human malignancies, HNSCC treatment strategies are mainly based on the tumor stage of the patient at first time diagnosis (3). For the determination of appropriate treatment strategies, it is pivotal to detect local lymph node metastases and thereby determine the nodal status of the neck (N-status) (4). The primary tumor of the vast majority of patients treated for HNSCC is removed by surgery. Depending on the primary tumor's T-category, its histopathological findings in terms of lymphangiosis carcinomatosa or depth of invasion and the presence of clinically obvious lymph node neck metastases (N+-status) surgical removal of the draining lymph node basin in the lateral neck (neck dissection) is recommended (5). However, in $20 \%$ of the patients that were determined to be positive for lymph node neck metastases by means of ultrasound and/or CT scans, preoperatively, histopathological examination of the tissue specimens derived from the lateral neck were classified to be pN0 (6). Vice versa, post-operative histopathological examination of neck dissection specimens revealed an estimated $30 \%$ of clinically N0 individuals finally showing metastases-positive lymph nodes in the neck (7). To improve the positive predictive value for metastasis of head and neck cancer, additional different and diverging approaches, apart from the above-mentioned regularly applied detection 
methods, have recently been made to identify molecular markers allowing to estimate the probability to develop metastases in the course of disease.

Molecular profiling of primary cancer tissues is one of these approaches. Recent studies investigated gene expression signatures to distinguish normal mucosa from cancer tissue and to predict the individual risk for metastasis and recurrence (8-10). Following this procedure, Rickman et al (8) identified a four-gene model (PSMD10, HSD17B12, FLOT2 and KRT17) that predicts the occurrence of metastases with a 77\% accuracy investigating a group of $79 \mathrm{HNSCC}$ patients. This prediction is supposed to be independent of clinical criteria (i.e. age, clinical lymph node status, tumor stage, differentiation and anatomical localisation of primary tumor). Furthermore, several genes have been described to be helpful markers to discover premalignant lesions and potentially to present targets for novel pharmacological interventions $(11,12)$. However, observations on the transcriptional level often are not directly reflected in the protein level, which might be explained by various posttranscriptional modifications, such as dsRNA cleavage by siRNA (13), microRNAs $(14,15)$ or histone modifications $(16)$ that may additionally influence the final protein level.

A genome-wide transcriptome dataset (data not shown, publication in progress) represented the starting point of this analysis identifying functional candidates as surrogate marker for metastasis of HNSCC. In the earlier study, several genes were shown to be differentially expressed when tissue specimens derived from metastatic and non-metastatic primary HNSCC, and they were investigated. Three transcripts out of these 331 differentially expressed genes were chosen for further validation because they previously had been associated to carcinogenesis and especially to metastasis: HERPUD1 (17), RAD51 (18-20) and SLPI (10). The SLPI gene on codes for the secretory leukocyte protease inhibitor located at chromosome 20q12, spans a region of $2.65 \mathrm{~kb}$ and consists of 4 exons and 3 introns. The SLPI protein is also called anti-leukoprotease. SLPI is a 11.7-kDa nonglycosylated kazal-type serine protease inhibitor of neutrophil elastase, cathepsin G (21), chymotrypsin and trypsin with 107 amino acids. It is produced by different cell types including breast, lung, endometrium, ovary, salivary glands and various host inflammatory and immune cells such as macrophages, neutrophils and B lymphocytes (22-24).

According to our previous microarray study results and hypothesizing that an SLPI decrease on the mRNA level in metastasized primary HNSCC might influence the process of metastasis in head and neck cancer, as suggested by others (10), we investigated the relevance of these findings by determining the SLPI mRNA level and the SLPI protein level. We conducted a quantitative real-time polymerase chain reaction (qRT-PCR) on 29 primary tumor specimens and an immunohistochemical analysis with a monoclonal anti-SLPI antibody on a large cohort of 121 metastatic and non-metastatic primary head and neck squamous cell carcinoma tissue specimens.

\section{Material and methods}

Tissue samples. Tissue samples were obtained from patients with HNSCC that were treated in the Department of Otorhinolaryngology, Head and Neck Surgery of the Christian Albrechts University of Kiel between 2004 and 2009. All samples were retrieved following informed consent approved by the local ethics committee. For RT-PCR analysis 29 tissue samples from patients with oropharyngeal and laryngeal squamous cell carcinoma (T1-T4) were collected (male, $\mathrm{n}=22$; female, $\mathrm{n}=7$ ). Patients' mean age was $62.4( \pm 9.1)$ years (Table I). According to the histopathological examination, 12 patients had no neck metastases (N0), 17 patients had neck metastases (N1-N3), and one patient had distant metastases. Additionally, for immunohistochemical staining tissue specimens derived from 121 independent patients with tumors at various anatomical tumor sites (T1-T4) in the head and neck region were analyzed (male, $\mathrm{n}=103$; female, $\mathrm{n}=18)$. Patients mean age was $60.9( \pm 9.7)$ years (Table II). Forty patients had no neck metastases (N0), 81 patients had neck metastases (N1-N3) and 6 patients had distant metastases. All samples were primary tumors. No metastatic sites were studied. Primary non-metastatic as well as primary metastatic tumors represented T-stages T1-T4.

RNA extraction and cDNA synthesis. Tissue samples were snap-frozen in liquid nitrogen immediately after sampling from the surgical tissue specimen. Seven $\mu \mathrm{m}$ thick frozen sections were cut in a cryotome (2800 Frigocut, Reichert-Jung, Germany). The sections were stained with hematoxylin and eosin (Merck, Germany), inspected under a microscope and the tumor areas were micro-dissected and stored in RNAlater (Ambion) for further processing. RNA was isolated and purified using the RNeasy mini-kit (Qiagen) and treated with DNase twice, using the Qiagen RNase-Free DNase set. RNA quality control was performed with the Agilent RNA 6000 Nano kit (Agilent Technologies). Total RNA and mRNA quality control criteria were applied in accordance with the Tumor Analysis Best Practices Working Group (25), discarding samples that did not meet these criteria. cDNA was obtained using the High Capacity cDNA RT kit from Quiagen.

qRT-PCR. qRT-PCR was performed with a TaqMan Assay from Applied Biosystems (Foster City, USA). RAD51 (Hs00153418_ m1), SLPI (Hs00268204_m1) and HERPUD1 (Hs00206652_m1) were analyzed. 18S (Hs99999901_s1) served as housekeeper and was used to normalize the results.

Immunohistochemistry. Paraffin-embedded tissue specimens were cut into 5- $\mu \mathrm{m}$ sections, deparaffinized, and rehydrated, followed by heat-induced epitope retrieval. Methanol containing $1 \%$ hydrogen peroxide was used to block the endogenous peroxidase for $10 \mathrm{~min}$. Sections were blocked with the corresponding preimmune serum for $15 \mathrm{~min}$ and incubated for $1 \mathrm{~h}$ with monoclonal primary antibody directed against SLPI (LifeSpan BioSciences, Seattle, WA) followed by incubation with a biotin-conjugated rabbit anti-mouse $\mathrm{IgG}$ secondary antibody (Dako, Hamburg, Germany) at room temperature for $30 \mathrm{~min}$. After washing with tris-buffered saline three times, a labelled peroxidase complex system (ABC-Vectorstain, Dako) was used to visualize all immune reactions. Finally, the specimens were counterstained with Mayer's hematoxylin and mounted with Permount (Fisher Scientific, Pittsburgh, PA). Small salivary glands served as internal positive controls. Negative controls were performed by replacing primary antibody with preimmune serum. 


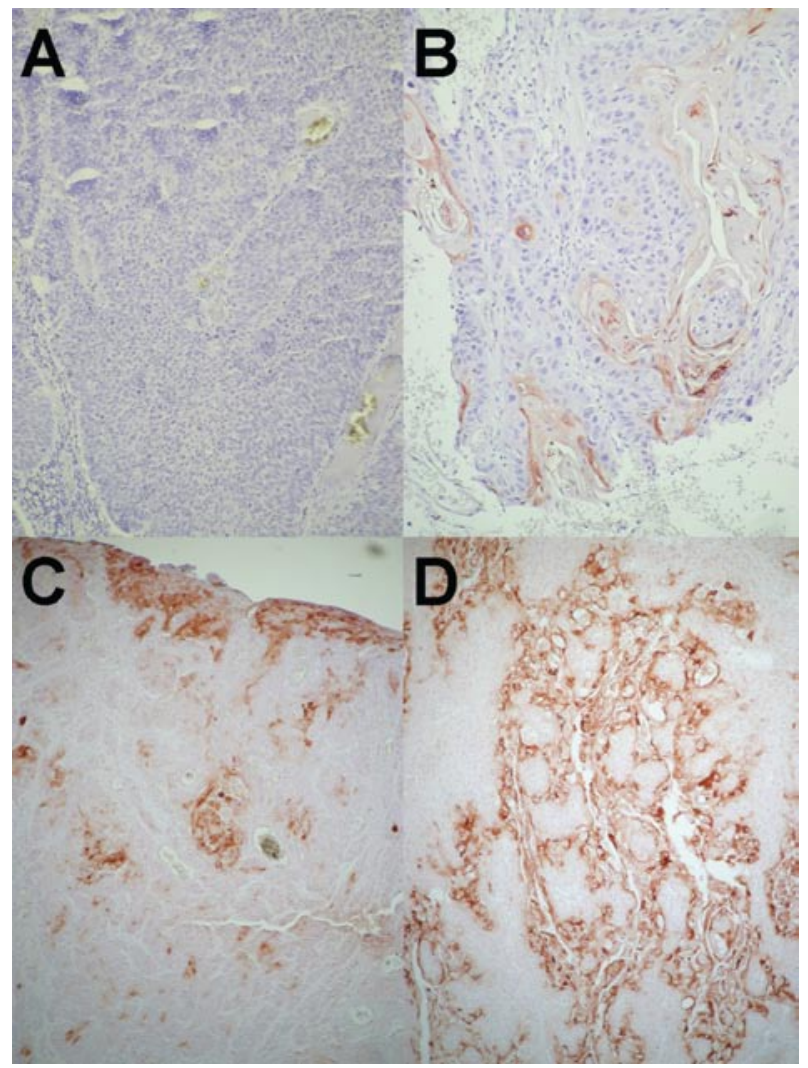

Figure 1. Immunohistochemistry of SLPI in HNSCC. (A) no immunoreactivity, (B) weak immunoreactivity, (C) moderate immunoreactivity and (D) strong immunoreactivity.

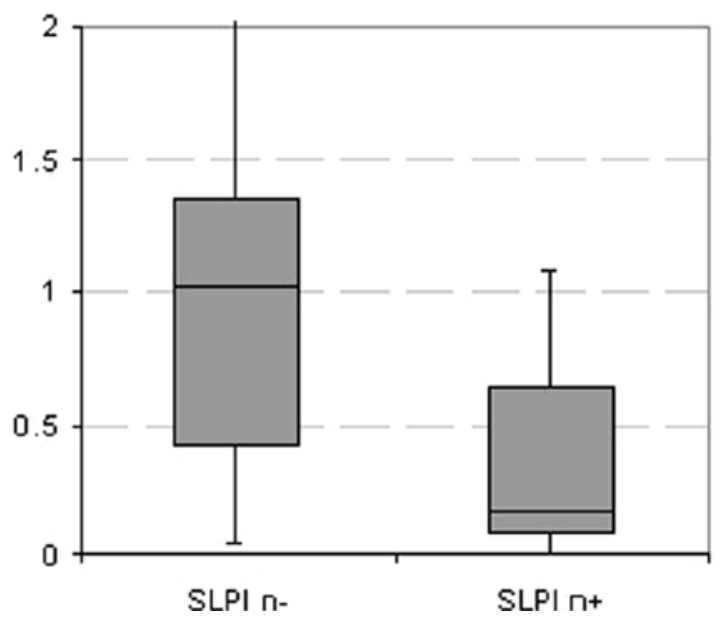

Figure 2. Result of the qRT-PCR analysis. SLPI is significantly lower expressed in metastatic HNSCC.

Evaluation of the immunohistochemical staining. The slides were reviewed by two of the authors (C.C. and T.G.) who confirmed the diagnosis and tumor grading. To assess SLPI protein levels, 300 cells in at least five areas were analyzed (x400 magnification). A mean percentage of positive tumor cells was determined and cases were assigned to one of the following categories: (-) <5\%; (I) 5-30\%, (II) $31-75 \%$ and (III) $>75 \%$ (Fig. 1). Cases with score of (-) were considered negative, cases with scores of (I-III) positive. To consider bias, the immunohisto- chemical and histopathological findings were additionally reviewed by an experienced pathologist (C.R.).

Statistical analysis. qRT-PCR: The Mann-Whitney U-test was used to determine differences between expression levels. Immunohistochemistry: means and standard deviations of percent positive cells were calculated per sample type and the Mann-Whitney U-test was used to compare expression between groups. To determine the false positive rate, a Westfall and Young permutation was performed (Westfall \& Young 1993, Resampling-Based Multiple Testing).

\section{Results}

$q R T-P C R$. The qRT-PCR for $18 \mathrm{~S}$ showed good quality RNA and sufficient and comparable amount of RNA from each source for the following specific qRT-PCR. The qRT-PCR with the sequence specific oligonucleotide primers for SLPI, HERPUD1 and RAD51 showed that SLPI expression in metastatic tumor tissue was 5.9-fold lower than in non-metastatic tissue $(p=0.0092$, false discovery rate $4.9 \%$ ) (Fig. 2). The analysis of HERPUD1 $(p=0.2634)$ and RAD51 $(p=0.3032)$ showed no statistical significant results.

Immunohistochemistry. SLPI was localized to the serous parts of the submucosal glands, in the cytoplasm of the epithelial cells of the upper aerodigestive tract and also in part in the cytoplasm of cancer cells. Especially the keratinized epithelial and cancer cells showed stronger SLPI expression. The statistical analysis of the immunohistochemical staining of the 121 HNSCC patients revealed a statistically significant difference between the N+ and N0 group with a $\mathrm{p}=0.0002$. A Westfall \& Young Permutation with 50,000 permutations revealed a fold-change of -1.79 and a false discovery rate of $0.14 \%$. The cohort additionally was sub-classified according to the patient's age in decades. Interestingly, patients between 60 and 69 years had a statistically significant lower expression of SLPI compared to younger patients $(40-49 \mathrm{p}=0.0063,50-59 \mathrm{p}=0.0049)$ as well as compared to older patients $(70-79 \mathrm{p}=0.031,80-89 \mathrm{p}=0.028)$. Stratification for the anatomical tumor site revealed a statistically significant higher SLPI expression in tumors of the hypopharynx when compared to the larynx ( $\mathrm{p}=0.0083$ ). The reason for this phenomenon remains yet unclear. Correlation of the other anatomical tumor sites revealed no statistically significant results. Sex ( $\mathrm{p}=0.5868)$, grading $(\mathrm{G} 1 / \mathrm{G} 2 \mathrm{p}=0.568, \mathrm{G} 2 / \mathrm{G} 3 \mathrm{p}=0.064, \mathrm{G} 1 / \mathrm{G} 3$ $\mathrm{p}=0.102)$, T-stage $(\mathrm{p}>0.05)$ and irradiation $(\mathrm{p}>0.05)$ or relapse of the disease $(p=0.2793)$ had no statistical relevance on the staining result (Fig. 3 and Table III).

\section{Discussion}

Parameters with predictive value for metastasis in head and neck cancer are of pivotal interest to determine patients that are likely to develop metastases in the course of disease and therefore should be treated in respect to this knowledge. To identify such parameters for HNSCC, we initially examined three genes (HERPUD1, RAD51 and SLPI) extracted out of our preceding microarray data, which have been described previously in association with metastasis and carcinogenesis. For HERPUD1 it has been reported that lower mRNA expression predicts the 


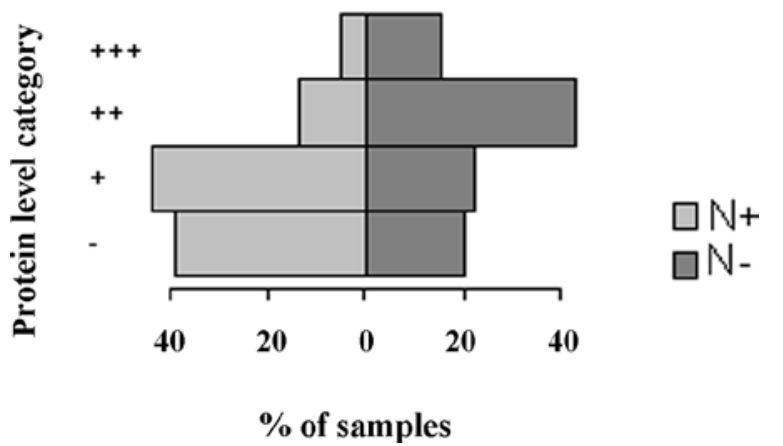

Figure 3. Results of the immunohistochemical staining with the monoclonal anti-SLPI antibody. One hundred and twenty-one samples are divided into N+ and N0. A statistically significant difference is observed between the groups $(\mathrm{p}=0.00027)$.

occurrence of metastases in prostate cancer (17); concerning RAD51 it was described that mRNA levels were increased in primary canine mammary adenocarcinomas and their lymph node metastases $(19,20)$. Finally, SLPI protein levels were shown to be elevated in tissue specimens derived from ovarian cancers without lymph node metastases in comparison to tissue specimens derived from lymph node metastasis-positive patients (26). Yet, out of these selected transcripts only the SLPI expression significantly differed when mRNA levels after qRT-PCR were compared in metastatic and non-metastatic HNSCC-derived tissue specimens. Therefore, further analysis was concentrated on this gene.

The SLPI gene is one out of several genes coding for a family of proteins with whey-acidic-protein (WAP) motifs. The WAP motif was first described in whey acidic protein, the main protein in milk of rats and mice. WAP proteins have one or more
WAP motifs consisting of about 50 amino acids with eight highly conserved cysteine residues that form four disulphide bridges (27). Four WAP genes have been identified as candidate molecular markers for various types of cancer (28): PI3 codes for elafin; SLPI for the SLPI protein (antileukoprotease); WFDC2 for WAP four-disulphide core domain protein 2 (previously called major human epididymis-specific protein 4, HE4); and WFDC1 for WAP four-disulphide core domain protein 1 (previously called prostate stromal protein $20 \mathrm{kDa}$, PS20) (28). SLPI seems to play an important role as a potent inhibitor of neutrophil elastase protecting the mucosa and skin against proteolysis $(22,29)$. Recent data imply an additional role of SLPI when reduced in the tumor cells in terms of setting free receptors for human papillomavirus proteins thus possibly giving rise to HPV infections (unpublished data). HPV DNA is detected in a substantial number of HNSCC (30) and therefore may play a yet to be determined role in the metastasis of this cancer.

In concordance with our preceding results on SLPI, differentially expressed SLPI mRNA levels have also been described for a variety of human cancers $(26,31)$. However, until now it remains unclear whether the mRNA expression level of SLPI had any impact on the development and progression of HNSCC especially towards neck metastasis. A Dutch laboratory group (10) demonstrated in a previously performed microarray analysis that, among several other genes, SLPI mRNA was downregulated in metastatic HNSCC compared to non-metastatic HNSCC, thus confirming the data of our previous study. To our knowledge, these results on diverging SLPI mRNA levels in tissue specimens of metastatic and non-metastatic HNSCC have not been observed, either by applying qRT-PCR techniques or by methods investigating the protein level of SLPI in the tumor cells. To assess whether the observations on the transcriptional level lead to similar changes on the protein level, we analysed

Table I. Patient data with TNM categories of primary tumors (qRT-PCR).

\begin{tabular}{|c|c|c|c|}
\hline & Larynx & Oropharynx & Overall \\
\hline Age years $($ mean $\pm S D)$ & $67.6(+7.7)$ & $58.7(+8.3)$ & $62.4(+9.1)$ \\
\hline Sex male/female $(\%)$ & $11 / 1(91.7 / 8.3)$ & $11 / 6(64.7 / 35.3)$ & $22 / 7(75.9 / 24.1)$ \\
\hline \multicolumn{4}{|l|}{ T stage } \\
\hline $\mathrm{T} 1(\%)$ & $0 \quad(0)$ & $3(17.6)$ & $3(10.4)$ \\
\hline $\mathrm{T} 2(\%)$ & $2(16.7)$ & $8(47.1)$ & $10(34.5)$ \\
\hline $\mathrm{T} 3(\%)$ & $4(33.3)$ & $1 \quad(5.9)$ & $5(17.2)$ \\
\hline $\mathrm{T} 4(\%)$ & $6 \quad(50)$ & $5(29.4)$ & $11(37.9)$ \\
\hline \multicolumn{4}{|l|}{$\mathrm{N}$ stage } \\
\hline N0 $(\%)$ & $5(41.7)$ & $7(41.2)$ & $12(41.4)$ \\
\hline N1 $(\%)$ & $1(8.3)$ & $3(17.6)$ & $4(13.8)$ \\
\hline $\mathrm{N} 2(\%)$ & $6 \quad(50)$ & $6(35.3)$ & $12(41.4)$ \\
\hline N3 (\%) & $0 \quad(0)$ & $1 \quad(5.9)$ & $1 \quad(3.4)$ \\
\hline \multicolumn{4}{|l|}{ M stage } \\
\hline M0 (\%) & $12(100)$ & $16(94.1)$ & $28(96.6)$ \\
\hline M1 (\%) & $0 \quad(0)$ & $1 \quad(5.9)$ & $1 \quad(3.4)$ \\
\hline
\end{tabular}


Table II. Patient data with TNM categories of primary tumors (Immunohistochemistry).

\begin{tabular}{|c|c|c|c|c|c|}
\hline & Larynx & Oropharynx & Hypopharynx & Oral cavity & Overall \\
\hline $\begin{array}{l}\text { Age years } \\
(\text { mean } \pm \mathrm{SD})\end{array}$ & $61.9( \pm 9.9)$ & $63.3( \pm 9.7)$ & $58.5( \pm 9.1)$ & $57.9( \pm 10.6)$ & $60.9( \pm 9.7)$ \\
\hline $\begin{array}{l}\text { Sex male/ } \\
\text { female }(\%)\end{array}$ & $\begin{array}{c}31 / 10 \\
(75.6 / 24.4)\end{array}$ & $\begin{array}{c}27 / 6 \\
(81.8 / 18.2)\end{array}$ & $\begin{array}{c}32 / 0 \\
(100 / 0)\end{array}$ & $\begin{array}{c}13 / 2 \\
(86.7 / 13.3)\end{array}$ & $\begin{array}{c}103 / 18 \\
(85.1 / 14.9)\end{array}$ \\
\hline $\begin{array}{l}\text { T stage } \\
\mathrm{T} 1(\%) \\
\mathrm{T} 2(\%) \\
\mathrm{T} 3(\%) \\
\mathrm{T} 4(\%)\end{array}$ & $\begin{array}{rr}2 & (4.9) \\
6 & (14.6) \\
21 & (51.2) \\
12 & (29.3)\end{array}$ & $\begin{array}{r}7(21.2) \\
7(21.2) \\
9(27.3) \\
10(30.3)\end{array}$ & $\begin{array}{rr}2 & (6.2) \\
7 & (21.9) \\
3 & (9.4) \\
20 & (62.5)\end{array}$ & $\begin{array}{lr}1 & (6.7) \\
6 & (40) \\
3 & (20) \\
5 & (33.3)\end{array}$ & $\begin{array}{lr}12 & (9.9) \\
26 & (21.5) \\
36 & (28.6) \\
47 & (38.8)\end{array}$ \\
\hline $\begin{array}{l}\text { N stage } \\
\text { N0 }(\%) \\
\text { N1 }(\%) \\
\text { N2 }(\%) \\
\text { N3 }(\%)\end{array}$ & $\begin{array}{r}18(43.9) \\
6(14.6) \\
15(36.6) \\
2 \quad(4.9)\end{array}$ & $\begin{array}{r}8(24.2) \\
6(18.2) \\
19(57.6) \\
0 \quad(0)\end{array}$ & $\begin{array}{rr}10 & (31.3) \\
1 & (3.1) \\
19 & (59.4) \\
2 & (6.2)\end{array}$ & $\begin{array}{lr}4 & (26.6) \\
3 & (20) \\
7 & (46.7) \\
1 & (6.7)\end{array}$ & $\begin{array}{rr}40 & (33.1) \\
16 & (13.2) \\
60 & (49.6) \\
5 & (4.1)\end{array}$ \\
\hline $\begin{array}{l}\text { M stage } \\
\text { Mx }(\%) \\
\text { M0 }(\%) \\
\text { M1 }(\%)\end{array}$ & $\begin{array}{rr}3 & (7.3) \\
35 & (83.4) \\
3 & (7.3)\end{array}$ & $\begin{array}{rr}0 & (0) \\
33 & (100) \\
0 & (0)\end{array}$ & $\begin{array}{rr}4 & (12.5) \\
26 & (81.3) \\
2 & (6.2)\end{array}$ & $\begin{array}{rr}1 & (6.7) \\
13 & (86.6) \\
1 & (6.7)\end{array}$ & $\begin{array}{rr}8 & (6.6) \\
107 & (88.4) \\
6 & (5.0)\end{array}$ \\
\hline
\end{tabular}

Table III. SLPI expression in primary tumors of different localisations.

\begin{tabular}{lccccc}
\hline & \multicolumn{3}{c}{ SLPI } \\
\cline { 2 - 5 } Localisation & - (Negative) & + & ++ & +++ & Total \\
\hline Oral cavity & 3 & 7 & 4 & 1 & 3 \\
Oropharynx & 10 & 13 & 7 & 1 & $33(27.3 \%)$ \\
Hypopharynx & 18 & 6 & 7 & $5(26.4 \%)$ \\
Larynx & 8 & 18 & 10 & $10(8.3 \%)$ & $41(33.9 \%)$ \\
Primary tumor & $39(32.2 \%)$ & $44(36.4 \%)$ & $28(23.1 \%)$ & 121 \\
\hline
\end{tabular}

a cohort of primary HNSCC specimens applying a monoclonal anti-SLPI antibody for immunohistochemistry. In addition to the already demonstrated downregulation of SLPI on the mRNA level, the results presented here also reveal a statistically significant downregulation of the SLPI protein expression in metastatic HNSCC derived tissue specimens. Lower expression of SLPI proteins in metastatic primary cancer has also been demonstrated for other human cancers, such as ovarian cancer (26). In contrast to our study results showing no correlation between the expression of SLPI and the degree of tumor differentiation, Alkemade et al (32) and Westin et al (33) demonstrated such a correlation in human epidermal tumors, which led to the hypothesis that SLPI protein levels potentially represent a surrogate marker for tumor progression.

The role and the mechanisms of action of SLPI in cancer development and metastasis are controversial. Expression of the SLPI gene is significantly increased by progesterone (34) and by the pro-inflammatory cytokines TNF- $\alpha$ and IL1- $\beta$ (35). Moreover, SLPI has been shown to be able to influence the invasive activity of cancer cells by inhibiting enzymes which are known to promote cancer invasion and progression $(36,37)$ and thereby acting as a protective protein against metastasis (26). Some authors postulated that absence or repression of the SLPI antiprotease function, as we observed in our metastatic tumor specimens, could promote tumor spread by enabling degradation of surrounding tissues by the tumor secreted proteases. Especially the inhibition of neutrophil elastase released by inflammatory cells or produced by tumor cells breaking down the structural proteins of the extracellular matrix surrounding the tumor thus leading to less restricted invasion and/or migration (38), might play an important role in tumor progression and might possibly explain the results of our study. A further explanation for the observations made in this study might be the fact that SLPI can suppress the production of matrix metalloproteinases, particularly MMP1 and MMP9, which have been extensively documented for their role in tumor invasion and metastasis $(39,40)$. Other authors also noted downregulation of the major inhibitors of $\mathrm{NF} \kappa \mathrm{B}$, including $\mathrm{NF} \kappa \mathrm{B}$ inhibitor $\alpha$ in a human cell culture model $(41,42)$. Therefore, the comparison and correlation of SLPI to pathways like the NFKB pathway 
might lead to further understanding of the complex mechanisms leading to metastasis in HNSCC.

Interestingly, several authors report on SLPI being overexpressed in human malignancies as pancreatic, papillary thyroid, uterine cervix, endometrial and ovarian cancer when compared to matched normal tissue derived specimens of the same patients (43-48). Likewise, SLPI-mRNA and SLPI-protein levels were found to be significantly overexpressed in HNSCC cancer tissue samples when compared to matched normal tissue controls (49). Therefore, overexpression of SLPI in any kind of tumor tissue is not suitable as a specific surrogate marker for a specific tumor entity. However, the above described data indicate that both regulation types obviously can coexist in human malignancies: higher levels of SLPI in cancer tissues in comparison to normal tissue controls as well as lower levels of SLPI in metastatic tissue in comparison to non-metastatic tissue. The data presented in the current study do not allow the decision of whether the level of SLPI in tumor tissue is up- or downregulated compared to normal mucosa, since no normal mucosa tissue controls of the upper respiratory tract were matched.

In conclusion, to our knowledge, this study demonstrates for the first time the potential relevance of SLPI in tumor progression to metastasis in primary HNSCC tissue. The results presented here clearly indicate the repression of SLPI, measurable on both mRNA and the protein level in metastatic HNSCC. Therefore, it can be assumed that SLPI might have a substantial impact on the metastatic process of HNSCC and may provide a possible therapeutic target for the treatment of metastasis in HNSCC. Ongoing studies focusing on SLPI and its molecular interaction partners, including HPV proteins and their receptors, in HNSCC may lead to further understanding of HNSCC progression mechanisms as well as to new concepts for prognostic and therapeutic approaches.

\section{Acknowledgements}

We thank Mrs. Dorina Oelsner and Mrs. Anne-Marie Røen for excellent technical assistance. This study was supported in part by a grant from the Werner \& Klara Kreitz Stiftung and the Dekanat of the Medical Faculty, University of Kiel, Germany. W. Martin Kast holds the Walter A. Richter Cancer Research Chair and is supported by NIH grant RC2 CA148298-01.

\section{References}

1. Parkin DM, Bray F, Ferlay J and Pisani P: Global cancer statistics, 2002. CA Cancer J Clin 55: 74-108, 2005.

2. Akervall J: Gene profiling in squamous cell carcinoma of the head and neck. Cancer Metastasis Rev 24: 87-94, 2005.

3. Chin D, Boyle GM, Porceddu S, Theile DR, Parsons PG and Coman WB: Head and neck cancer: past, present and future. Expert Rev Anticancer Ther 6: 1111-1118, 2006.

4. Pantel K and Brakenhoff RH: Dissecting the metastatic cascade. Nat Rev Cancer 4: 448-456, 2004.

5. Robbins KT, Clayman G, Levine PA, et al: Neck dissection classification update: revisions proposed by the American Head and Neck Society and the American Academy of OtolaryngologyHead and Neck Surgery. Arch Otolaryngol Head Neck Surg 128: 751-758, 2002.

6. Woolgar JA: Pathology of the N0 neck. Br J Oral Maxillofac Surg 37: 205-209, 1999.

7. Jones AS, Phillips DE, Helliwell TR and Roland NJ: Occult node metastases in head and neck squamous carcinoma. Eur Arch Otorhinolaryngol 250: 446-449, 1993.
8. Rickman DS, Millon R, De Reynies A, et al: Prediction of future metastasis and molecular characterization of head and neck squamous-cell carcinoma based on transcriptome and genome analysis by microarrays. Oncogene 27: 6607-6622, 2008.

9. Gottschlich S, Ambrosch P, Cordes C, Görögh T, Schreiber S and Häsler R: Gene expression profiling of head and neck squamous cell carcinoma using cDNA microarrays. Int J Oncol 29: 605-613, 2006.

10. Roepman P, Wessels LFA, Kettelarij N, et al: An expression profile for diagnosis of lymph node metastases from primary head and neck squamous cell carcinomas. Nat Genet 37: 182-186, 2005.

11. Leethanakul C, Knezevic V, Patel V, et al: Head and Neck Cancer Genome Anatomy Project: Gene discovery in oral squamous cell carcinoma through the Head and Neck Cancer Genome Anatomy Project: confirmation by microarray analysis. Oral Oncol 39: 248-258, 2003.

12. Ginos MA, Page GP, Michalowicz BS, et al: Identification of a gene expression signature associated with recurrent disease in squamous cell carcinoma of the head and neck. Cancer Res 64: 55-63, 2004.

13. Siomi $\mathrm{H}$ and Siomi MC: On the road to reading the RNAinterference code. Nature 457: 396-404, 2009.

14. Chang SS, Jiang WW, Smith I, et al: MicroRNA alterations in head and neck squamous cell carcinoma. Int J Cancer 123: 2791-2797, 2008.

15. Lujambio A and Esteller M: How epigenetics can explain human metastasis: a new role for microRNAs. Cell Cycle 8: 377-382, 2009.

16. Cedar $\mathrm{H}$ and Bergman Y: Linking DNA methylation and histone modification: patterns and paradigms. Nat Rev Genet 10: 295-304, 2009.

17. Hendriksen PJM, Dits NFJ, Kokame K, et al: Evolution of the androgen receptor pathway during progression of prostate cancer. Cancer Res 66: 5012-5020, 2006.

18. Klein HL: The consequences of Rad51 overexpression for normal and tumor cells. DNA Repair 7: 686-693, 2008.

19. Klopfleisch R and Gruber AD: Increased expression of BRCA2 and RAD51 in lymph node metastases of canine mammary adenocarcinomas. Vet Pathol 46: 416-422, 2009.

20. Klopfleisch R, Schütze M and Gruber AD: RAD51 protein expression is increased in canine mammary carcinomas. Vet Pathol 47: 98-101, 2010.

21. Boudier C, Cadène $M$ and Bieth JG: Inhibition of neutrophil cathepsin $\mathrm{G}$ by oxidized mucus proteinase inhibitor. Effect of heparin. Biochemistry 38: 8451-8457, 1999.

22. Franken C, Meijer CJ and Dijkman JH: Tissue distribution of antileukoprotease and lysozyme in humans. J Histochem Cytochem 37: 493-498, 1989.

23. Abe T, Kobayashi N, Yoshimura K, et al: Expression of the secretory leukoprotease inhibitor gene in epithelial cells. J Clin Invest 87: 2207-2215, 1991.

24. Jin FY, Nathan C, Radzioch D and Ding A: Secretory leukocyte protease inhibitor: a macrophage product induced by and antagonistic to bacterial lipopolysaccharide. Cell 88: 417-426, 1997.

25. Expression profiling - best practices for data generation and interpretation in clinical trials. Nat Rev Genet 5: 229-237, 2004.

26. Nakamura K, Takamoto N,Hongo A, et al: Secretory leukoprotease inhibitor inhibits cell growth through apoptotic pathway on ovarian cancer. Oncol Rep 19: 1085-1091, 2008.

27. Hennighausen LG and Sippel AE: Mouse whey acidic protein is a novel member of the family of 'four-disulfide core' proteins. Nucleic Acids Res 10: 2677-2684, 1982.

28. Bouchard D, Morisset D, Bourbonnais Y and Tremblay GM: Proteins with whey-acidic-protein motifs and cancer. Lancet Oncol 7: 167-174, 2006.

29. Hiemstra PS: Novel roles of protease inhibitors in infection and inflammation. Biochem Soc Trans 30: 116-120, 2002.

30. Ang KK, Harris J, Wheeler R, et al: Human papillomavirus and survival of patients with oropharyngeal cancer. N Engl J Med 363: 24-35, 2010.

31. Li S, Ross DT, Kadin ME, Brown PO and Wasik MA: Comparative genome-scale analysis of gene expression profiles in $\mathrm{T}$ cell lymphoma cells during malignant progression using a complementary DNA microarray. Am J Pathol 158: 1231-1237, 2001

32. Alkemade HA, van Vlijmen-Willems IM, van Haelst UJ, van de Kerkhof PC and Schalkwijk J: Demonstration of skinderived antileukoproteinase (SKALP) and its target enzyme human leukocyte elastase in squamous cell carcinoma. J Pathol 174: 121-129, 1994. 
33. Westin U, Nyström M, Ljungcrantz I, Eriksson B and Ohlsson K The presence of elafin, SLPI, IL1-RA and STNFalpha RI in head and neck squamous cell carcinomas and their relation to the degree of tumour differentiation. Mediators Inflamm 11: 7-12, 2002.

34. King AE, Morgan K, Sallenave J and Kelly RW: Differential regulation of secretory leukocyte protease inhibitor and elafin by progesterone. Biochem Biophys Res Commun 310: 594-599, 2003.

35. Sallenave JM, Shulmann J, Crossley J, Jordana M and Gauldie J: Regulation of secretory leukocyte proteinase inhibitor (SLPI) and elastase-specific inhibitor (ESI/elafin) in human airway epithelial cells by cytokines and neutrophilic enzymes. Am J Respir Cell Mol Biol 11: 733-741, 1994.

36. Del Rosso M, Fibbi G, Pucci M, D'Alessio S, Del Rosso A, Magnelli L and Chiarugi V: Multiple pathways of cell invasion are regulated by multiple families of serine proteases. Clin Exp Metastasis 19: 193-207, 2002.

37. Sun $Z$ and Yang P: Role of imbalance between neutrophil elastase and alpha 1-antitrypsin in cancer development and progression. Lancet Oncol 5: 182-190, 2004.

38. Yamaguchi K, Shimada S, Tashima S and Ogawa M: A potentially novel peptidase, resembling but distinct from neutrophil elastase, produced by carcinoma cells. Oncol Rep 7: 1017-1021, 2000.

39. Zhang Y, DeWitt DL, McNeely TB, Wahl SM and Wahl LM: Secretory leukocyte protease inhibitor suppresses the production of monocyte prostaglandin $\mathrm{H}$ synthase-2, prostaglandin E2, and matrix metalloproteinases. J Clin Invest 99: 894-900, 1997.

40. Nelson AR, Fingleton B, Rothenberg ML and Matrisian LM: Matrix metalloproteinases: biologic activity and clinical implications. J Clin Oncol 18: 1135-1149, 2000.

41. Hu Y, Sun H, Drake J, et al: From mice to humans: identification of commonly deregulated genes in mammary cancer via comparative SAGE studies. Cancer Res 64: 7748-7755, 2004.
42. Taggart CC, Greene CM, McElvaney NG and O'Neill S: Secretory leucoprotease inhibitor prevents lipopolysaccharide-induced IkappaBalpha degradation without affecting phosphorylation or ubiquitination. J Biol Chem 277: 33648-33653, 2002.

43. Iacobuzio-Donahue CA, Ashfaq R, Maitra A, et al: Highly expressed genes in pancreatic ductal adenocarcinomas: a comprehensive characterization and comparison of the transcription profiles obtained from three major technologies. Cancer Res 63: 8614-8622, 2003.

44. Jarzab B, Wiench M, Fujarewicz K, et al: Gene expression profile of papillary thyroid cancer: sources of variability and diagnostic implications. Cancer Res 65: 1587-1597, 2005.

45. Rein DT, Breidenbach M, Nettelbeck DM, et al: Evaluation of tissue-specific promoters in carcinomas of the cervix uteri. J Gene Med 6: 1281-1289, 2004.

46. Zhang D, Simmen RCM, Michel FJ, Zhao G, Vale-Cruz D and Simmen FA: Secretory leukocyte protease inhibitor mediates proliferation of human endometrial epithelial cells by positive and negative regulation of growth-associated genes. J Biol Chem 277: 29999-30009, 2002.

47. Hough CD, Cho KR, Zonderman AB, Schwartz DR and Morin PJ: Coordinately up-regulated genes in ovarian cancer. Cancer Res 61: 3869-3876, 2001.

48. Israeli O, Goldring-Aviram A, Rienstein S, Ben-Baruch G, Korach J, Goldman B and Friedman E: In silico chromosomal clustering of genes displaying altered expression patterns in ovarian cancer. Cancer Genet Cytogenet 160: 35-42, 2005.

49. Dasgupta S, Tripathi PK, Qin H, Bhattacharya-Chatterjee M, Valentino $\mathrm{J}$ and Chatterjee SK: Identification of molecular targets for immunotherapy of patients with head and neck squamous cell carcinoma. Oral Oncol 42: 306-316, 2006. 